\title{
ANÁLISE ENUNCIATIVA DE CANTO PARA MINHA MORTE, DE RAUL SEIXAS
}

\author{
Ernani Cesar de Freitas \\ Débora Facin
}

Resumo: Este artigo constitui um estudo enunciativo do gênero discursivo letra de música e tem como objetivo analisar o sentido de morte que se depreende da letra da música Canto para minha morte, de Raul Seixas, mediante a relação intersubjetiva entre o locutor e o interlocutor. Menciona-se a proposta da subjetividade na linguagem, teoria na qual Benveniste aborda as marcas de pessoa, espaço e tempo como categorias que validam essa tese. A pesquisa caracteriza-se como descritivo-qualitativa. Os procedimentos metodológicos utilizados consistem na identificação e análise das marcas que norteiam a subjetividade e como estas se organizam em uma relação intersubjetiva. Com base nos achados, sugere-se que o jogo das marcas linguísticas (pessoa, espaço e tempo) em Canto para a minha morte evidencia a construção progressiva de sentidos sobre a morte.

Palavras-chave: Enunciação. Intersubjetividade. Letra de música.

\section{INTRODUÇÃO}

Partindo-se da hipótese de que a marcas que denunciam a subjetividade na linguagem possibilitam analisar a relação intersubjetiva entre o locutor e o interlocutor, pretendemos analisar neste artigo o sentido de morte que se depreende da letra da música Canto para minha morte, do álbum Há 10 mil anos atrás de Raul Seixas (1976). A fundamentação teórica deste estudo de caráter descritivo-qualitativo concentra-se em Émile Benveniste ([1946] 2005a, [1956] 2005b, [1958] 2005c, [1966] 2006c, [1970] 2006a). Para dar conta desse objetivo, estruturamos este artigo em mais três seções. Na segunda seção, apresentamos alguns conceitos-chave da enunciação em Benveniste, para que possamos situar as noções que procedem dessa teoria e justificarmos o porquê de um estudo linguístico voltado à enunciação. Na terceira

\footnotetext{
* Professor do mestrado em Letras da Universidade de Passo Fundo e do mestrado em Processos e Manifestações Culturais da Universidade Feevale (Novo Hamburgo, RS). Doutor em Letras pela PUCRS. Pós-doutorado em Linguística Aplicada e Estudos da Linguagem (PUC-SP/LAEL). Email: ecesar@upf.br.

** Mestranda em Letras na Universidade de Passo Fundo (UPF). Especialista em Linguística e Ensino pela Universidade Comunitária Regional de Chapecó (Unochapecó); Especialista em Produção e Revisão de Textos pela Unochapecó. Email: deborafacin@hotmail.com.
} 
seção abordamos a metodologia e analisamos a letra da música. $\mathrm{Na}$ quarta seção, apresentamos as considerações finais destacando algumas conclusões e possíveis estudos que a teoria da enunciação de Benveniste proporciona.

\section{A TEORIA DA ENUNCIAÇÃO: O USO DA LÍNGUA SEGUNDO ÉMILE BENVENISTE}

Privilegiar a orientação teórica de Benveniste tem um motivo: ele é considerado o pai da linguística da enunciação. Com base em pressupostos estruturalistas, Benveniste filia-se a Saussure e conserva os princípios estruturais da língua em sua teoria; contudo, não estaciona. Benveniste vai além, ao contemplar o "homem na língua"; a novidade está em articular sujeito e estrutura:

Benveniste libertou os linguistas presos às amarras da teoria saussuriana. Ele lhes devolveu a subjetividade, o mundo e o discurso que se faz sobre ele; Benveniste reatou com a filosofia e aproximou-se da psicologia social e da pragmática, reencontrou a virtude do diálogo e da interação. Enfim, uma Linguística diferente. (NORMAND, 2009, p. 197).

Normand (2009) aborda o parentesco entre Saussure e Benveniste e qualifica a linguística benvenistiana como "diferente". Isso porque Benveniste atribui uma característica ímpar aos estudos da linguagem: a singularidade. Para ele, "a enunciação é este colocar em funcionamento a língua por um ato individual de utilização" (BENVENISTE, 2006a, p. 82). Se é individual, o locutor faz uso da palavra elegendo mecanismos próprios, em uma ação que é sempre inédita e irrepetível.

Nesse sentido, é importante ressaltar que falar em enunciação não significa reduzi-la à fala, ou seja,

$\mathrm{o}$ ato individual pelo qual se utiliza a língua introduz em primeiro lugar o locutor como parâmetro nas condições necessárias da enunciação. Antes da enunciação, a língua não é senão possibilidade da língua. Depois da enunciação, a língua é efetuada em uma instância de discurso [...] (BENVENISTE, 2006a, p. 83-84). 
Há aqui outra familiaridade entre Saussure e Benveniste: a preocupação metodológica. Enquanto Saussure procurou encontrar na língua razões para defini-la como objeto de estudo, Benveniste parte dos aspectos formais da língua, porém atribui o sentido à forma para estabelecer o domínio do discurso (NORMAND, 2009).

Pensar a teoria da enunciação de Benveniste implica conceber a língua em uma perspectiva social. $\mathrm{O}$ homem se define na e pela linguagem. É importante destacar que no artigo $D a$ subjetividade na linguagem, Benveniste (1958/2005c) alerta para o fato de que a linguagem não constitui um instrumento de comunicação; tanto é que o autor apela a comparações reducionistas, como picareta, flecha, roda, justamente para enfatizar que a língua não é um instrumento passível de ser "fabricado". O homem é capaz de falar em virtude de seu aparelho fonológico; ele se apropria da língua para falar com outro homem, com o mundo.

A Teoria da Enunciação de Benveniste fundamenta-se na presença do sujeito na língua. Não se trata aqui, pois, do sujeito empírico, mas de um sujeito que é demarcado linguisticamente, que é construído tão somente na chamada instância do discurso. O homem constitui-se como tal por meio da linguagem. Segundo o autor, a subjetividade é a capacidade do locutor de apropriar-se da língua em determinado tempo e espaço e se colocar como sujeito (da enunciação).

\subsection{Categoria de pessoa: noção primeira para o constructo da subjetividade}

É com o tratado dos pronomes que a subjetividade ganha corpo, ocupando uma posição privilegiada na teoria benvenistiana. Nesse particular, Benveniste chama a atenção para a ideia ingênua da universalidade dos pronomes e torna notório o apelo da não unicidade destes:

A universalidade dessas formas e dessas noções faz pensar que o problema dos pronomes é ao mesmo tempo um problema de linguagem e um problema de línguas por ser, em primeiro lugar, um problema de linguagem. É como fato de linguagem que o apresentaremos aqui, para mostrar que os pronomes não constituem uma classe unitária, mas espécies diferentes segundo o modo de linguagem do qual são os signos. (BENVENISTE, 2005b, p. 277).

FREITAS; FACIN - Análise enunciativa de Canto para minha morte... 
Para Benveniste, não há a possibilidade de insistirmos em uma teoria que engessa tal categoria em classes. A pessoalidade só é válida para eu e tu, os quais pertencem à instância discursiva e validam a doutrina de Benveniste, que é justamente o fato de a enunciação ser um ato inédito. Cada situação, sempre, consiste em um enunciado novo, pois, no momento em que o locutor (eu) implica um tu, ele está marcado na língua. Essa trajetória de locutor a sujeito - do discurso - instiga-nos a refletir sobre a particularidade dos pronomes pessoais (eu, tu) e como essa perspectiva constitui por excelência a linguagem como condição para a comunicação humana.

Com a categoria de pessoa e não-pessoa, há as categorias de espaço (aqui) e tempo (agora), as quais delimitam a instância contemporânea do discurso que contém eu (BENVENISTE, 2005b, p. 279). Trata-se do momento atual e espaço correspondentes à enunciação, cada vez única, "porque a enunciação é o lugar de instauração do sujeito e este é o ponto de referência das relações espaço-temporais, ela é o lugar do ego, hic et nunc." (FIORIN, 2010, p. 42). Benveniste (2005c) assevera que é inconcebível uma língua sem expressão de pessoa; o que pode acontecer é que, em determinadas línguas, os pronomes sejam omitidos, como é o caso das sociedades do Extremo Oriente, porém o fato de serem implícitos já denota sua importância.

Em Estrutura das relações de pessoa no verbo, Benveniste (2005a) mostra o problema do conceito de pessoalidade: "A forma dita terceira pessoa comporta realmente uma indicação de enunciado sobre alguém ou alguma coisa, mas não referida a uma pessoa específica" (BENVENISTE, 2005a, p. 250). Em relação à não-pessoa, precisamos situar também o processo que ocorre em nós e vós. Segundo a teoria da enunciação de Benveniste, o nós não condiz com o plural de eu, nem o vós consiste em um plural de tu. O que acontece é a união de um eu com um não-eu:

Tanto o uso de nós se amplifica em uma pessoa mais solene, com maior autoridade no nós majestático, quanto se amplifica em uma pessoa mais difusa, com contornos indefinidos no nós de orador on de autor. A mesma análise é feita para vós, tanto no uso coletivo quanto no uso de polidez a passagem do tu ao vós exprime pessoa generalizada (FLORES et al., 2008, p. 79, grifo do autor). 
Quanto à definição dos pronomes, a gramática tradicional insiste em tê-los como equivalentes. Todavia, a noção de pessoa não está para todos. $\mathrm{Na}$ enunciação, torna-se fundamental um olhar particular acerca das características de cada pessoa: o eu, o ser subjetivo, que instaura um tu, este não-subjetivo; ambos em oposição a ele, que não corresponde à marca de pessoa.

Benveniste (2005b) atribui algumas características à não pessoa as quais distanciam o pronome ele da condição de pessoalidade, quais sejam: a referenciação pode ser atribuída a qualquer objeto ou a nenhum; ele jamais pertence à instância do discurso; o número de variantes pronominais ou demonstrativas que ele comporta é bastante acentuado; ele não é compatível com as categorias de espaço e tempo - aqui e agora.

No início desta seção, ressaltamos que os pronomes pessoais são o marco inicial para a fundamentação da subjetividade na linguagem. Além dos pronomes pessoais, também comportam a propriedade dêitica os demonstrativos, advérbios, adjetivos, que organizam as relações de espaço e tempo em torno do sujeito.

\subsection{Aqui e agora: uma reflexão do espaço e tempo no discurso}

A dêixis, quando não associada à enunciação, corresponde a uma classe vazia; logo, os elementos dêiticos definem-se em relação à instância de discurso sob dependência do eu que enuncia (BENVENISTE, 2005c). Os pronomes demonstrativos e certos advérbios organizam o espaço em que o eu se enuncia. Não se trata aqui, pois, de um espaço físico, mas sim o ambiente interno e externo da enunciação. Aqui e aí definem o espaço interno: aí em relação ao tu e aqui, ao eu; em oposição, aquele, que diz respeito à não pessoa (ele), remete à parte externa da enunciação.

Em última análise, a categoria de tempo é outro indicador da subjetividade na linguagem. Qualquer que seja a língua, esta é sempre organizada em razão do tempo, o qual pode ser marcado pelo verbo ou pelas palavras. O tempo em uma língua sempre será marcado, quer em um futuro, quer em um passado; no entanto, sempre em referência a um presente. Este "tem como referência temporal um dado lingüístico: a coincidência do acontecimento descrito com a instância de discurso que 
o descreve" (BENVENISTE, 2005c, p. 289). Para Benveniste (2005c), o tempo de que se fala aqui é o inerente ao exercício da linguagem, o tempo do momento da fala; trata-se do tempo linguístico, que é suireferencial.

Segundo Benveniste (2006b), há um tempo específico da língua; contudo, antes de reconhecê-lo, é necessário esclarecer duas outras noções de tempo. Em primeira instância, temos o tempo físico, que é linear, infinito, contínuo; por exemplo, o calendário. Em segundo plano, há o tempo crônico, que é o tempo dos acontecimentos, ou melhor, o retrato da nossa vida demarcada em acontecimentos. No tempo crônico, “denominamos 'tempo' a continuidade em que se dispõem em série estes blocos distintos que são os acontecimentos. Porque os acontecimentos não são o tempo, eles estão no tempo. Tudo está no tempo, exceto o próprio tempo" (BENVENISTE, 2006b, p. 71, grifo do autor). O tempo físico e o tempo crônico organizam a vida em sociedade; há uma série de referências que informam ao homem onde este se encontra na história em meio aos acontecimentos.

O terceiro nível de tempo é o tempo linguístico. Benveniste (2006b, p. 74) deixa claro que "uma coisa é situar um acontecimento no tempo crônico, outra coisa é inseri-lo no tempo da língua". O tempo linguístico diz respeito ao fato de que, cada vez que o locutor enuncia, ele atualiza o acontecimento, ou seja, o discurso é reinventado a cada momento de fala. $\mathrm{Na}$ realidade da linguagem, o tempo que há é sempre o presente, o tempo do momento da fala, o qual é implícito. Desse modo, o tempo linguístico comporta suas próprias divisões independentemente do tempo crônico.

Falar em enunciação implica a referência ao eu, tu/aqui/agora. No decorrer desta seção, observamos que o conjunto de dêixis constitui categorias vazias quando não empregadas em uma instância discursiva. As palavras na língua só se tornam plenas quando tomadas por um locutor que se apropria do aparelho formal da enunciação para se enunciar; trata-se do eu que instaura o tu em um espaço ímpar (o do discurso) em um tempo que é sempre contemporâneo.

A próxima seção é dedicada à análise dos dados. 


\section{ANÁLISE DOS DADOS}

Antes de apresentar a análise dos dados, cabe destacar aspectos metodológicos. O método deste trabalho caracteriza-se como descritivoqualitativo. O corpus de análise constitui a letra da música Canto para minha morte, composição de 1976 do álbum Há 10 mil anos atrás de Raul Seixas. Procuramos, mediante a categoria de pessoa, construir subsídios que comportassem como referência o ato discursivo, uma vez que "o essencial é [...] a relação entre o indicador (neste caso, as pessoas) e a presente instância de discurso" (BENVENISTE, 2005b, p. 280).

Benveniste, em sua concepção intersubjetiva, destaca a subjetividade como condição intrínseca à intersubjetividade: eu (pessoa subjetiva) instaura o tu (pessoa não subjetiva) em relação a ele (não pessoa). Fica claro aqui que o objetivo é uma investigação enunciativa; a ênfase da análise não está na letra da música em si, mas na forma como ela foi produzida, nas marcas linguísticas reveladoras da intersubjetividade.

Ante essas considerações, para melhor organizarmos as observações, a análise baseou-se nos seguintes procedimentos:

a) primeiramente, procedemos a uma leitura compreensiva da letra Canto para minha morte, com a finalidade de esclarecermos o sentido, em um quadro geral, da morte;

b) no segundo momento, identificamos as evidências linguísticas caracterizadas pelas marcas de pessoa na composição que denunciam o fundamento da subjetividade;

c) na sequência, fizemos uma leitura intersubjetiva para entendermos como a inversibilidade ocorre em Canto para minha morte e quais as evidências que fundam essa "conversa" entre locutor (eu) e interlocutor (tu) em oposição a ele (não-pessoa), neste caso, ela, a morte. Segundo Flores e Teixeira (2008, p. 33), "essa inversibilidade assegura a intersubjetividade sem a qual não faz sentido falar de categoria linguística de pessoa";

d) por fim, identificamos as marcas de tempo para descrever o tempo linguístico no discurso; concomitante a isso, as marcas que caracterizam o espaço da enunciação. Os tempos verbais e os advérbios serão analisados em consonância com a categoria de pessoa, uma vez que a noção do $e u / t u$, aqui, agora é o que constitui o conceito de intersubjetividade. 
Considerações metodológicas feitas, apresentamos a seguir a letra da música Canto para minha morte, de Raul Seixas.

\section{Canto para minha morte}

Raul Seixas

Eu sei que determinada rua que eu já passei não tornará ouvir o som dos meus passos

Tem uma revista que eu guardo há muitos anos e que nunca mais eu vou abrir

Cada vez que eu me despeço de uma pessoa pode ser que essa pessoa esteja me vendo pela última vez

A morte, surda, caminha ao meu lado e eu não sei em que esquina ela vai me beijar

Com que rosto ela virá?

Será que ela vai deixar eu acabar o que eu tenho que fazer?

Ou será que ela vai me pegar no meio do copo de uísque

Na música que eu deixei para compor amanhã?

Será que ela vai esperar eu apagar o cigarro no cinzeiro?

Virá antes de eu encontrar a mulher, a mulher que me foi destinada,

E que está em algum lugar me esperando

Embora eu ainda não a conheça?

Vou te encontrar vestida de cetim, pois em qualquer lugar esperas só por mim

E no teu beijo provar o gosto estranho que eu quero e não desejo, mas tenho que encontrar

Vem, mas demore a chegar. Eu te detesto e amo morte, morte, morte

Que talvez seja o segredo desta vida

Morte, morte, morte que talvez seja o segredo desta vida 
Qual será a forma da minha morte? Uma das tantas coisas que eu não escolhi na vida?

Existem tantas... um acidente de carro. O coração que se recusa a bater no próximo minuto

A anestesia mal aplicada. A vida mal vivida, a ferida malcurada, a dor já envelhecida

O câncer já espalhado e ainda escondido, ou até, quem sabe

Um escorregão idiota, num dia de sol, a cabeça no meio-fio...

Oh morte, tu que és tão forte, que matas o gato, o rato e o homem

Vista-se com a tua mais bela roupa quando vieres me buscar

Que meu corpo seja cremado e que minhas cinzas alimentem a erva

E que a erva alimente outro homem como eu porque eu continuarei neste homem

Nos meus filhos, na palavra rude que eu disse para alguém que não gostava

E até no uísque que eu não terminei de beber aquela noite...

Vou te encontrar vestida de cetim, pois em qualquer lugar esperas só por mim

E no teu beijo provar o gosto estranho que eu quero e não desejo, mas tenho que encontrar

Vem, mas demore a chegar. Eu te detesto e amo morte, morte, morte

Que talvez seja o segredo desta vida

Morte, morte, morte que talvez seja o segredo desta vida

A letra Canto para minha morte constitui um tango dedicado à morte, composto por sete estrofes irregulares, que mostram de forma misteriosa as incertezas que permeiam o fim da vida. A introdução da composição, primeira estrofe, discorre sobre os fatos que não mais acontecerão quando a morte chegar, quais sejam: os sons dos passos, a revista 
nunca mais aberta, uma pessoa nunca mais vista. O que se percebe, nesse momento, é que a morte corresponde à certeza, certeza esta revelada em cada acontecimento não mais possível.

$\mathrm{Na}$ segunda e terceira estrofes, a certeza de que a morte é a única verdade do homem é substituída pelo mistério de como esse momento se passará. O mistério é marcado mediante uma série de interrogações:

\section{Com que rosto ela virá}

Será que ela vai deixar eu acabar o que eu tenho que fazer?

Ou será que ela vai me pegar no meio do copo de uísque

$\mathrm{Na}$ música que eu deixei para compor amanhã?

Será que ela vai esperar eu apagar o cigarro no cinzeiro?

Virá antes de eu encontrar a mulher, a mulher que me foi destinada,

E que está em algum lugar me esperando

Embora eu ainda não a conheça?

Temos aqui a urgência do conhecimento acerca do "rosto" da morte.

$\mathrm{Na}$ quarta estrofe, a incerteza sobre o fim da vida e as indagações de como isso se processará cedem lugar ao conformismo, mostrado de modo paradoxal em decorrência da aceitação e de repulsa. Vejamos:

Vou te encontrar vestida de cetim, pois em qualquer lugar esperas só por mim

E no teu beijo provar o gosto estranho que eu quero e não desejo, mas tenho que encontrar

Vem, mas demore a chegar. Eu te detesto e amo morte, morte, morte

Que talvez seja o segredo desta vida/Morte, morte, morte que talvez seja o segredo desta vida. 
A quinta estrofe inicia com uma interrogação - Qual será a forma da minha morte? - que reitera de que maneira a morte se apresentará; a marca "forma" presente no questionamento é traduzida posteriormente, nesta mesma estrofe, por meio de descrições, ou seja, possíveis acontecimentos que podem concretizar a morte.

A sexta estrofe revela o diálogo com a morte; de início, a interjeição "Oh morte" induz a conversa e esta é mantida por meio de desejos que são projetados para um período pós-morte. A última estrofe corresponde ao estribilho que ressalta a dúvida, o conformismo e também a objeção.

Em síntese, mediante uma leitura geral, percebemos a atitude de aceitação e certeza ante a morte; no entanto, a postura direciona-se, sobremaneira, para um comportamento de inquietude em virtude de como será o "rosto" da morte.

Apresentamos a seguir uma análise enunciativa da composição, buscando identificar as marcas de pessoa que denunciam a subjetividade na linguagem.

$\mathrm{Na}$ primeira estrofe, a pessoalidade demarcada é de um locutor que se propõe como sujeito do discurso. Isso acontece pela presença do pronome eu e pelas marcas verbais. Segundo Benveniste (2005b, p. 278, grifo do autor), "eu significa a pessoa que enuncia a presente instância de discurso que contém eu". A subjetividade fortemente presente nos pronomes e nos verbos é que delineia o percurso intersubjetivo projetado no discurso. Vejamos: "Eu sei”, "passei”, “meus passos”, “eu guardo", "eu vou", “eu me despeço", "me vendo", "meu lado", "não sei", "me beijar"; estas evidências garantem o valor subjetivo do enunciado. Consoante Benveniste (2005c, p. 286, grifo do autor), trata-se do "ego que diz ego. Encontramos aí o fundamento da 'subjetividade' que se determina pelo status lingüístico de "pessoa".

Ainda a respeito da primeira estrofe, a partir da relação intersubjetiva entre eu (locutor) e tu (interlocutor), depreende-se o sentido de morte que situa o interlocutor, o ouvinte da música, em uma instância de simulacro acerca da morte, demarcada por inquietações. Quando o locutor toma a palavra e se marca discursivamente como eu, o interlocutor - tu, implícito no texto - identifica-se com a morte de forma abstrata, projetada, distante, apenas a reconhece como o fim que em 
algum instante se concretizará. Uma vez que as propriedades que definem a enunciação são a irrepetibilidade e a singularidade, no momento em que o locutor (eu) se apropria do aparelho formal da língua e instaura o interlocutor (tu), a referência constrói-se tão somente no discurso. Assim, quando o eu se marca no discurso, automaticamente notifica o tu; juntos, eles instituem a chamada situação de enunciação, a qual, para Benveniste (2006a, p. 84), manifesta-se "por um jogo de formas específicas cuja função é de colocar o locutor em relação constante e necessária com sua enunciação”. No caso da primeira estrofe da letra da música Canto para minha morte, os índices de pessoa determinam o centro de referência interno da enunciação - eu sei, passei, eu guardo, vou abrir, me despeço, etc. - a partir do qual se evoca uma resposta do tu, que está presente como interlocutor, neste caso, implícito na enunciação. No contexto enunciativo, a língua expressa certa relação com o mundo; é inerente, para o locutor, a referência "pelo discurso, e, para o outro, a possibilidade de co-referir identicamente, no consenso pragmático que faz de cada locutor um co-locutor. A referência é parte integrante da enunciação" (BENVENISTE, 2006a, p. 84). É desse modo que o ouvinte da música se identifica com o sentido enigmático de morte apresentado pelo eu.

$\mathrm{Na}$ sequência, segunda estrofe, o locutor vale-se de interrogações para influenciar o comportamento do interlocutor. Para Benveniste (2006a, p. 86), a interrogação demanda uma resposta, ou seja, "desde o momento em que o enunciador se serve da língua para influenciar de algum modo o comportamento do alocutário, ele dispõe para este fim de um aparelho de funções". A função aqui é o questionamento; a inquietude manifestada pelo locutor a respeito da forma de sua morte. Outra característica da enunciação é que Benveniste (2006a, p. 87) chama de "acentuação da relação discursiva com o parceiro"; este pode ser real ou imaginado, individual ou coletivo. No momento em que o locutor invoca o interlocutor mediante as interrogações acerca da morte dispostas na letra da música, temos a estrutura de um diálogo - o quadro figurativo da enunciação. À medida que a narrativa se desenvolve, o sentido depreendido do corpus constrói-se numa relação que se estende desde o mistério, passando pelo medo, até a aceitação. O locutor inicia convocando o interlocutor mediante a asserção (na primeira estrofe), visando a comunicar o tu com certeza de que a morte é um fenômeno 
que procede, em algum momento e de alguma forma, para, posteriormente, indagar "como" a morte "virá".

O distanciamento, este caracterizado pelas marcas de não pessoa, vai se exaurindo à medida que outras marcas familiares à categoria de pessoa fazem parte da enunciação - a interrogação. Esse mesmo processo persiste na terceira estrofe: o sujeito que se enuncia - "eu apagar", "eu encontrar", "me foi destinada", "me esperando", "eu ainda" - e fala sobre a morte, na marca de não-pessoa - "ela vai". De acordo com a teoria dos pronomes, a terceira pessoa - na composição, "ela" comporta a característica de aposição, uma vez que "não designa especificamente nada nem ninguém" (BENVENISTE, 2005a, p. 253).

Ainda que na segunda e terceira estrofes haja marcas que correspondam a uma estrutura de ordem enunciativa - as interrogações -, a não-pessoa demarcada em "ela" é privada da correlação de personalidade. Proceder a uma análise enunciativa dessa natureza é importante para entendermos como se constrói o sentido de morte na composição, ou seja, temos, em primeira instância, o distanciamento e a não-aceitação, esta constituída como uma coisa, ninguém, a não-pessoa, ela.

Atentemos agora para a quarta estrofe:

Vou te encontrar vestida de cetim, pois em qualquer lugar esperas só por mim

E no teu beijo provar o gosto estranho que eu quero e não desejo, mas tenho que encontrar

Vem, mas demore a chegar. Eu te detesto e amo morte, morte, morte

Que talvez seja o segredo desta vida

Morte, morte, morte que talvez seja o segredo desta vida

Nesse momento, o que prevalece é outra variedade de diálogo e que Benveniste (2006a, p. 87) o inscreve na enunciação: é o monólogo. Para o autor, trata-se de um "diálogo interiorizado, formulado em 'linguagem interior', entre um eu locutor e um eu ouvinte (ela agora é 
personificada como tu). Às vezes, o eu locutor é o único a falar; e o eu ouvinte permanece, entretanto, presente; sua presença é necessária e suficiente para tornar significante a enunciação do eu locutor". Se a enunciação é cada vez única e tem a finalidade de aproximar locutor e interlocutor por algum tipo de relação, percebemos na quarta estrofe que o diálogo entre o eu locutor e o eu ouvinte intimam a morte como se esta fizesse parte da interação. O tratamento atribuído a ela é diferente do retratado nas primeiras três estrofes; isso porque a personificação prevalece em expressões como: "vestida de cetim", "teu beijo", "gosto estranho", a fim de aproximá-la e, com isso, camuflar a incerteza e o medo expressos nas passagens anteriores. Destacamos, nesse particular, o que Benveniste (2006c) afirma sobre a construção do sentido:

o sentido de uma frase é outra coisa diferente do sentido das palavras que a compõem. O sentido de uma frase é sua idéia, o sentido de uma palavra é seu emprego (sempre na acepção semântica). A partir da idéia, a cada vez particular, o locutor agencia palavras que neste emprego tem um 'sentido' particular (BENVENISTE, 2006c, p. 231, grifo nosso).

O agenciamento de expressões como "vestida de cetim", "teu beijo" e "gosto estranho", possíveis para atribuições a seres humanos, reitera o sentido personificado da morte, sobretudo reforça a familiaridade dela para com o locutor e o interlocutor. $\mathrm{O}$ recurso de intimação por parte do locutor implica uma relação "viva" com o interlocutor, imprescindível à enunciação. No âmbito enunciativo, a cada vez que o locutor agencia palavras, estas comportam forma e sentido diferentes; nas expressões analisadas, o sentido inesperado revela-se porque considera a referência construída de morte tão somente nesta situação. Por exemplo, o termo "cetim", de acordo com o Dicionário Houaiss da Língua Portuguesa (2009), significa "tecido de seda lustroso e macio cuja trama não aparece no lado avesso; o que é macio, acetinado". A palavra "cetim", porém, adquire outro sentido. Quando o locutor deseja que a morte esteja vestida de cetim, é porque o tecido "cetim" é algo fino, delicado, leve; e é assim que o eu deseja encontrá-la. 
Ainda no que se refere à quarta estrofe, a asserção denota a presença marcante do locutor na enunciação, cada vez única e irrepetível. A asserção é, pois,

a manifestação mais comum da presença do locutor na enunciação, ela tem mesmo instrumentos específicos que a exprimem ou que a implicam, as palavras sim e não afirmando positivamente ou negativamente uma proposição. A negação como operação lógica é independente da enunciação, ela tem sua forma própria, que é não. Mas a partícula assertiva não, substituta de uma proposição, classifica-se como partícula sim, com a qual ela reparte o estatuto, nas formas que dizem respeito à enunciação (BENVENISTE, 2006a, p. 86, grifo do autor).

Consoante o autor, nas passagens "que eu quero e não desejo, mas tenho que encontrar" e "Vem, mas demore a chegar. Eu te detesto e amo morte, morte, morte", avaliamos as atitudes que o locutor provoca no interlocutor; trata-se, ao mesmo tempo, de desejo e recusa da asserção. Essas evidências conferem à enunciação o que Benveniste (2006a) chama de quadro figurativo da enunciação; locutor (eu) e interlocutor (tu) são protagonistas da enunciação.

“Qual será a forma da minha morte?” É urgente, nessa introdução da quinta estrofe, a presença subjetiva. Eis aqui duas características marcantes da enunciação: o eu que enuncia - minha morte - e a interrogação, propriedade esta de que tratamos anteriormente. Esta, para Benveniste (2006a), suscita uma resposta, processo que deriva do aspecto enunciativo. A quinta estrofe, apresentada na sequência, ilustra a função da interrogação em um quadro enunciativo.

Qual será a forma da minha morte? Uma das tantas coisas que eu não escolhi na vida?

Existem tantas... um acidente de carro. O coração que se recusa a bater no próximo minuto

A anestesia mal aplicada. A vida mal vivida, a ferida malcurada, a dor já envelhecida

O câncer já espalhado e ainda escondido, ou até, quem sabe

Um escorregão idiota, num dia de sol, a cabeça no meio-fio... 
O eu que enuncia, por meio de perguntas, provoca no interlocutor certo comportamento. Esse comportamento constitui as respostas ao questionamento do $e u$, as quais revelam as possíveis formas de morte: "acidente de carro", "o coração que se recusa a bater no próximo minuto", "a anestesia mal aplicada", "a vida mal vivida", "a ferida malcurada", "a dor já envelhecida", "o câncer já espalhado e ainda escondido", "um escorregão idiota, num dia de sol, a cabeça no meiofio". Essa relação entre locutor e interlocutor configura a intersubjetividade na linguagem, intrínseca à enunciação.

Outra marca que institui a intersubjetividade como um derivado da enunciação é o que Benveniste (2006a) denomina de intimação, forma já abordada nesta análise. Isso acontece, também, na sexta estrofe no momento em que o eu instaura o tu mediante uma série de apelos, por exemplo:

Oh morte, tu que és tão forte, que matas o gato, o rato e o homem

Vista-se com a tua mais bela roupa quando vieres me buscar

Que meu corpo seja cremado e que minhas cinzas alimentem a erva

E que a erva alimente outro homem como eu porque eu continuarei neste homem

Nos meus filhos, na palavra rude que eu disse para alguém que não gostava

E até no uísque que eu não terminei de beber aquela noite...

Em resumo, por meio da identificação das marcas de pessoa, viabilizamos um estudo enunciativo o qual permitiu a construção do sentido de morte particular no decorrer da letra ilustrada no "tango da morte". Entendemos o que Benveniste (2006a) chama de quadro figurativo da enunciação, o qual se consolida tão somente por uma estrutura dialógica. Segundo Benveniste (2005c), a intersubjetividade é condição para a comunicação humana; sem essa condição, não faz sentido tratarmos da categoria de pessoa. 
Em consonância com a categoria dêitica de pessoa, há uma série de outros elementos dêiticos que definem o tempo e o espaço da enunciação. A partir desse momento, identificamos marcas no "tango da morte" que denotam a instância discursiva mediante advérbios e tempos verbais.

Interessa a uma pesquisa enunciativa o tempo linguístico: "O tempo do discurso nem se reduz às divisões do tempo crônico nem se fecha em uma subjetividade solipsista. Ele funciona como um fator de intersubjetividade" (BENVENISTE, 2006b, p. 78). A identificação das formas verbais foi imprescindível para o entendimento da intersubjetividade no corpus. São várias as formas que, embora se apresentem no passado ou futuro, remetem tão só à chamada instância do discurso. No início da narrativa, visualizamos marcas de não-pessoa direcionadas à morte; nesse momento, as marcas verbais no passado e no futuro são predominantes e, com a categoria de pessoa (eu) em relação a tu (interlocutor ouvinte da música), conferem o significado de morte como algo que é distante e projetado. O tempo verbal (primeira estrofe) marcado no passado é atualizado pelo enunciador que reflete que ela (a morte) o impossibilita de abrir a revista, despedir-se de alguém.

Os tempos verbais conjugados no particípio (quinta estrofe) exprimem possíveis coincidências de acontecimentos que são contemporâneos ao momento de fala: aplicada, vivida, malcurada, envelhecida, espalhado, escondido. Eu, nesse caso, "vai ao encontro do tempo ou o tempo ao encontro dele, segundo a imagem que anima nossa representação" (BENVENISTE, 2006b, p. 75). Essa representação pode remeter ao passado ou futuro, particularmente a forma misteriosa com que a morte pode-se apresentar, porém sempre atualizada pelo discurso, momento de fala.

O tempo cronológico é evidente na composição: conformismo sobre fatos não mais concretizados após a morte e o mistério traduzido em possibilidades de como o fim chegará; no entanto, o eu torna contemporâneas as inquietações acerca de sua morte.

Assim como o tempo, o espaço se organiza a partir do eu. De acordo com Benveniste (2005b, p. 279), “aqui e agora delimitam a instância espacial e temporal co-extensiva e contemporânea da presente instância de discurso que contém eu". Sobre o espaço, na composição de 
Raul Seixas, a expressão-chave "qualquer lugar" corresponde à morte de qualquer um, em qualquer lugar e qualquer tempo. A morte de que o locutor fala é a sua morte, a morte do tu, visto que a morte pode acontecer em qualquer hora, em qualquer lugar e eu está em todos esses espaços. "Qualquer espaço", sob a perspectiva enunciativa, consiste no espaço linguístico. Conforme Fiorin (2010, p. 262), "todos os objetos são [localizados a partir do hic], sem que tenha importância seu lugar no mundo, pois aquele que os situa se coloca como centro e ponto de referência da localização". O ponto de localização, no "tango da morte", inscreve-se a partir do eu/morte, em "qualquer lugar" que contém eu.

No "tango da morte", a interação verbal se consolida a partir da posição do locutor que instaura o tu (ouvinte da música) no discurso e, a partir dessa relação, o sentido de morte vai-se construindo progressivamente em uma espécie de narrativa: desde a certeza de que a morte virá, independentemente de como ela se apresentará, as menções às possíveis formas da morte, os desejos de o locutor ter uma morte "vestida de cetim", até a decisão de encontrá-la.

\section{CONSIDERAÇÕES FINAIS}

A iniciativa de desenvolver um estudo voltado à enunciação, especificamente aos pressupostos de Émile Benveniste, considerou o objetivo de analisar o sentido de morte que se depreende da letra da música Canto para minha morte, de Raul Seixas, mediante a relação intersubjetiva entre o locutor e o interlocutor. A teoria da enunciação benvenistiana viabilizou pensar o funcionamento da língua de modo ímpar; isso porque, a cada vez que o locutor se apropria do aparelho formal da língua para se enunciar e instaura o tu, a relação entre os participantes da enunciação foi revelando o sentido inesperado de morte, o qual se altera a cada estrofe, a cada forma de que o locutor se serve para influenciar o interlocutor acerca da morte, a cada situação de enunciação.

Ratificamos que, sob o viés enunciativo, as palavras não se limitam ao sentido dicionarizado; elas têm sentido único; é o locutor que as escolhe e as define de acordo com a instância enunciativa. Exemplo disso é a morte que veste cetim, que beija, que tem gosto estranho, que veste bela roupa. Na letra da música, o fato de a enunciação comportar o 
caráter inédito, a cada recorrência à da palavra "morte", o interlocutor é levado a encarar a morte como algo misterioso, incerto, ameaçador. No entanto, à medida que o locutor modaliza a forma da morte, esta se mostra, ao mesmo tempo, como desejo e repulsa, mas bela.

O percurso desta análise privilegiou os conceitos-chave das categorias que denunciam a subjetividade na linguagem e, a partir destas, investigamos a intersubjetividade, quais sejam: pessoa, espaço e tempo, bem como os recursos expressivos das palavras que legitimam a enunciação. Procedemos a um estudo linguístico identificando as categorias de pessoa, espaço e tempo a fim de verificar as marcas que denunciam a subjetividade na linguagem, visando à relação intersubjetiva para a construção do sentido no "tango da morte".

Este estudo teve como aporte teórico os artigos de Benveniste (1946, 1956, 1958, 1966, 1970), e de alguns leitores de Benveniste, como Fiorin (2010), Flores e Teixeira (2008), Normand (2009). É no processo de o locutor se apropriar do aparelho formal da língua e se propor como sujeito que as marcas deste se declaram e validam o discurso.

Acreditamos que a teoria da enunciação, de Benveniste, proporciona pensar a língua a partir de um sujeito que fala, não o sujeito em si, mas sim as marcas deixadas por ele e o sentido que se constrói com esses rastros. A noção de enunciação consolida-se na renovação, novidade esta que só é possível porque o locutor se propõe como sujeito para se enunciar e carece do outro, do tu. Segundo Benveniste (2005c, p. 286), "a consciência de si mesmo só é possível se experimentada pelo contraste". É justamente essa polaridade que torna possível a comunicação humana.

Depois de analisarmos o sentido de morte, na composição de Raul Seixas, a partir da relação de intersubjetividade, finalizamos com a seguinte passagem do texto Por que gosto de Benveniste, de Roland Barthes (2004, p. 211-212, grifo do autor): “o sujeito não é anterior à linguagem; só se torna sujeito na medida em que fala; em suma, não há 'sujeitos' (e, portanto, não há 'subjetividade'), há apenas locutores; bem mais - e isso é relembrado incessantemente por Benveniste -, só há interlocutores”. 


\section{REFERÊNCIAS}

BARTHES, R. Por que gosto de Benveniste. In: O rumor da língua. 2. ed.

Trad. de Mario Laranjeira. São Paulo: Martins Fontes, 2004. p. 207-213.

BENVENISTE, É. (1946). Estrutura das relações de pessoa no verbo. In: - Problemas de linguistica geral I. Campinas: Pontes, 2005a. . (1956). A natureza dos pronomes. In: . Problemas de linguística geral I. Campinas: Pontes, 2005b. . (1958). Da subjetividade na linguagem. In: Problemas de linguística geral I. Campinas: Pontes, 2005c. - (1963). Vista d'olhos sobre o desenvolvimento da linguística. In: . Problemas de linguística geral I. Campinas: Pontes, 2005d. . (1970). O aparelho formal da enunciação. In: Problemas de linguística geral II. Campinas: Pontes, 2006a. . (1965). A linguagem e a experiência humana. In: Problemas de linguística geral II. Campinas: Pontes, 2006b. - (1966). A forma e o sentido na linguagem. In: Problemas de linguistica geral II. Campinas: Pontes, 2006c.

DICIONÁRIO HOUAISS DA LÍNGUA PORTUGUESA. Rio de Janeiro: Objetiva, 2009. Versão eletrônica.

FIORIN, J. L. As astúcias da enunciação: as categorias de pessoa, espaço e tempo. São Paulo: Ática, 2010.

FLORES, V. do N.; BARBISAN, L. B.; FINATTO, M. J. B.; TEIXEIRA, M. Dicionário de linguística da enunciação. São Paulo: Contexto, 2009.

FLORES, V. do N.; SILVA, S.; LICHTENBERG, S.; WEIGERT, T. Enunciação e gramática. São Paulo: Contexto, 2008.

FLORES, V. do N.; TEIXEIRA, M. Introdução à linguística da enunciação: São Paulo: Contexto, 2008.

Enunciação, dialogismo, intersubjetividade: um estudo sobre Bakhtin e Benveniste. Bakhtiniana: Revista de Estudos do Discurso, São Paulo, v. 1, n. 2, p. 143-164, 2009. Disponível em: <http://revistas.pucsp. br>. Acesso em: 5 ago. 2011.

NORMAND, C. Convite à linguística. São Paulo: Contexto, 2009.

POSSENTI, S. Os humores da língua: análises lingüísticas de piadas. Campinas: Mercado de Letras, 1998.

SAUSSURE, F. de. Curso de linguística geral. São Paulo: Cultrix, 2006. 
Recebido em: 29/08/11. Aprovado em: 23/08/12.

Title: Enunciative analysis of Canto para minha morte, by Raul Seixas

Authors: Ernani Cesar de Freitas; Débora Facin

Abstract: the present paper constitutes an enunciative study of the discursive genre of song lyrics and aims at analyzing the sense of death, which arises from the lyrics of the song Canto para minha morte, by Raul Seixas, in face of the intersubjective relation between the speaker and listener. The proposition of instersubjectivity in language, a theory in which Benveniste approaches the marks of person, space and time as categories that validate such a thesis is mentioned. The research is descriptive-qualitative. The methodological procedures employed were the identification and analysis of the marks that guide subjectivity and how these marks are organized in an intersubjective relation. Based on such findings, it is suggested that the play of linguistic marks (person, space, time) in Canto para minha morte makes evident the progressive construction of meanings of death.

Keywords: Enunciation. Intersubjectivity. Song lyrics.

Título: Análisis enunciativo de Canto para mi muerte, de Raul Seixas Autores: Ernani Cesar de Freitas; Débora Facin

Resumen: Este articulo constituye un estudio enunciativo del género discursivo letra de canción y tieen como objetivo analizar el sentido de muerte que se deprende de la letra de la canción Canto para mi muerte, de Raul Seixas, mediante la relación intersubjetiva entre el locutor y el interlocutor. Se menciona la propuesta de la subjetividad en el lenguaje, teoría en la cual Benveniste aborda las marcas de persona, espacio y tiempo como categorias que validan esa tesis. La pesquisa se caracteriza como descriptivacualitativa. Los procedimientos metodológicos utilizados consisten en la identificación y análisis de las marcas que orientan la subjetividady como éstas se organizan en una relación intersubjetiva. Con base en los hallargos, se sugiere que el juego de las marcas lingüisticas (persona, espacio y tiempo) en Canto para mi muerte evidencia la construcción progresiva de sentidos sobre la muerte.

Palabras-clave: Enunciación. Intersubjetividad. Letra de canción.

FREITAS; FACIN - Análise enunciativa de Canto para minha morte... 